\title{
DESENVOLVIMENTO, AVALIAÇÃO FÍSICO - QUÍMICA, SENSORIAL E COLORIMÉTRICA DA GELEIA DE SERIGUELA DIET
}

\section{DEVELOPMENT, SENSORY, PHYSICAL-CHEMICAL AND COLORIMETRIC CHARACTERISTICS OF DIET SERIGUELA JAM}

\author{
Juliete Pedreira Nogueira ${ }^{1}$, Maria Antônia Carvalho Lima de Jesus ${ }^{2}$ \\ ${ }^{1,2}$ Universidade Estadual de Feira de Santana - UEFS - Feira de Santana - Brasil \\ airamcarvalho@gmail.com
}

\begin{abstract}
Resumo
Atualmente tem se observado uma grande demanda por alimentos sem açúcar. Essa tendência tem encorajado o uso de frutas como ingredientes de muitos produtos, como geleias, permitindo assim obter produtos de baixo valor calórico. A seriguela (Spondias purpurea L.) é uma fruta tropical produzida comumente no Nordeste brasileiro e usá-la na produção de geleia pode garantir o consumo da fruta durante o ano inteiro e reduzir perdas da produção, pois é naturalmente um fruto perecível. Diante disso, o objetivo do presente trabalho foi o desenvolvimento e a caracterização de geleia de seriguela elaborada sem adição de açúcar, e com uso dos edulcorantes sucralose $e$ acessulfame de potássio, submetendo-a a análises físico químicas, sensoriais e de cor. As geleias apresentaram características físico-químicas similares a outras geleias presentes na literatura. A análise sensorial revelou que a formulação mais aceita apresentou a combinação dos dois edulcorantes. Com relação a análise colorimétrica, as geleias apresentaram coloração amarronzada provavelmente pela formação dos pigmentos em maior intensidade resultantes do processamento. Os resultados encontrados nesse estudo são de grande interesse para as agroindústrias, uma vez que abre uma nova possibilidade de aproveitamento da seriguela com uma alternativa de fornecimento de um produto de baixa caloria.
\end{abstract}

Palavras-chave: seriguela; geleia; valor calórico; edulcorantes.

\section{Introdução}

A cirigueleira (Spondias purpurea L.), originária da América Tropical, produz a seriguela, fruto tipo drupa de cor vermelho-escura quando maduro, que possui polpa de coloração amarela, aroma e sabor agradáveis. Devido sua excelente qualidade organoléptica, a seriguela é muito apreciada no Nordeste brasileiro, refletido pelo contínuo aumento do consumo do fruto in natura ou processado na forma de diversos produtos, normalmente disponibilizados no mercado, o que tem proporcionado crescente interesse para seu cultivo comercial (LEON e SHAW, 1990; LIMA, 2009). 
Alimentos sem adição de açúcar e com baixo valor calórico foram inicialmente desenvolvidos para consumidores com problemas de saúde específicos, como os diabéticos, mas o consumo desses alimentos expandiu-se devido a uma preocupação crescente da população com a saúde, com o controle do peso, dieta e estilo de vida mais saudáveis (SANDROU e ARVANITOYANNIS, 2000). Existe uma grande demanda por alimentos sem açúcar ou com o teor reduzido deste nutriente, mas que mantenham suas propriedades sensoriais como gosto, aroma e textura similares a dos respectivos produtos convencionais. Esta demanda tem encorajado o uso de frutas como ingredientes de muitos produtos como por exemplo geleias permitindo assim obter produtos de baixo valor calórico (BARCIA et al. 2010; HOLM et al. 2000).

Geleia é o produto obtido pela cocção, de frutas inteiras ou em pedações, polpa ou suco de frutas, com açúcar e água e concentrado até consistência gelatinosa de forma que quando extraídas de seus recipientes, sejam capazes de se manterem no estado semi-sólido (BAKER, 2005).

Geleias com reduzido valor calórico são elaboradas pela substituição total ou parcial da sacarose por edulcorantes alternativos como sucralose, acesulfame de potássio, ou, combinação destes com agentes de corpo como sorbitol, maltitol, polidextrose. $\mathrm{O}$ agente gelificante é a pectina BTM (baixo teor de metoxilação), com menos de $50 \%$ dos grupos carboxilas esterificado, sendo frequentemente usada em produtos sem ou com baixo teor de açúcar devido a suas propriedades de formação do gel sem ou com uma pequena quantidade de açúcar na presença de íons de cálcio (LOFGREN e HERMANSSON, 2007).

O acessulfame de potássio é um edulcorante artificial não nutritivo cujo poder adoçante é duzentas vezes maior que a sacarose. Apresenta estabilidade em altas temperaturas (até $225^{\circ} \mathrm{C}$ ), alta solubilidade em água sendo estável em uma ampla faixa de $\mathrm{pH}$ e, em soluções contendo outros edulcorantes apresenta efeito sinérgico (EMBRAFARMA, 2010; WOLFHARD e LIPINSKI, 1985). A legislação permite seu uso respeitando o limite máximo de 35 miligramas por 100 gramas de alimento (BRASIL, 2008).

A sucralose apresenta excelentes características como a estabilidade em altas temperaturas normalmente usadas no processamento de alimentos. Excelente estabilidade em meios de $\mathrm{pH}$ baixo, não sendo hidrolisada durante a digestão em virtude da estabilidade das ligações carbono-cloro. É, portanto, um edulcorante estável que tem o perfil sensorial similar ao da sacarose, mas que não tem calorias e é aproximadamente 600 vezes mais doce que a sacarose. Foi liberado para uso no Brasil desde 1995 (BINNS, 2003; BRASIL, 1995; WIET e BEYTS, 1992). Os edulcorantes sucralose e acessulfame de potássio têm sido muito utilizados em produtos a base de frutas (ALMEIDA et al. 2009; BARCIA et al. 2010; GRANADA et al. 2005; MARTINS, 2008; MENDONÇA et al. 2005; NACHTIGALL e ZAMBIAZI, 2006). 
O objetivo deste trabalho foi o desenvolvimento e a caracterização de geleia de seriguela elaborada sem adição de açúcar, submetendo-a a análises físico químicas, sensoriais e de cor.

\section{Material e Métodos}

\section{Material}

As seriguelas utilizadas no experimento foram adquiridas no comércio de frutas da cidade de Feira de Santana - Ba. A Pectina de Baixo Teor de Metoxilação (BTM) e a goma xantana foram doadas pela CPKelco Brasil S/A. Os edulcorantes sucralose e acessulfame de potássio foram cedidos pela Tovani Benzaquen Ltda (Brasil) e Nutramax Ltda (Brasil). O conservante sorbato de potássio foi doado pela Kerry (Brasil). O fosfato tricálcico e o ácido cítrico, ambos de grau alimentício foram adquiridos da empresa Synth (Brasil).

\section{Métodos}

Foram desenvolvidas cinco formulações de geleia de seriguela diet e uma formulação convencional com adição de açúcar. Nas formulações dietéticas variou-se o percentual de edulcorantes respeitando os limites mínimo e máximo definidos com base na legislação para edulcorantes (BRASIL, 2008). Os percentuais dos edulcorantes foram: F1: 0,01\% de sucralose; F2: 0,025\% de acessulfame; F3: 0,015\% de sucralose e 0,006\% de acessulfame; F4: 0,02\% de sucralose e 0,02\% de acessulfame; F5: 0,015\% de sucralose e 0,025\% de acessulfame. Os demais ingredientes tiveram valores fixos para todas as formulações: Pectina BTM - 1,3\%; Goma xantana 0,2\%; Ácido cítrico - 0,2\%; Fosfato tricálcico - 40mg por g de pectina e Conservante Sorbato de Potássio $-0,05 \%$.

Os ingredientes usados na geleia convencional foram: Pectina de Alto Teor de Metoxilação (ATM) - 2\%; Ácido cítrico - 3\% e Relação suco/sacarose - 50/50.

O desenvolvimento das geleias de seriguela diet e convencional foi realizado no Laboratório de Desenvolvimento de Novos Produtos e de Processamento de Alimentos da Universidade Estadual de Feira da Santana - UEFS. O processamento da geleia de seriguela diet encontra-se na Figura 1 e o da geleia de seriguela convencional encontra-se na Figura 2.

Após a recepção das seriguelas, ocorreu a etapa de seleção quando os frutos deteriorados foram eliminados. Em seguida os frutos sadios foram lavados e sanitizados com água clorada a 100ppm por 15 minutos sendo em seguida despolpados utilizando um despolpador de bancada (modelo compacta, Itametal), usando tela de 1,5 $\mathrm{mm}$. 
Figura1 - Fluxograma do processamento das geleias de seriguela diet.

Seriguela in natura $\rightarrow$ Recepção

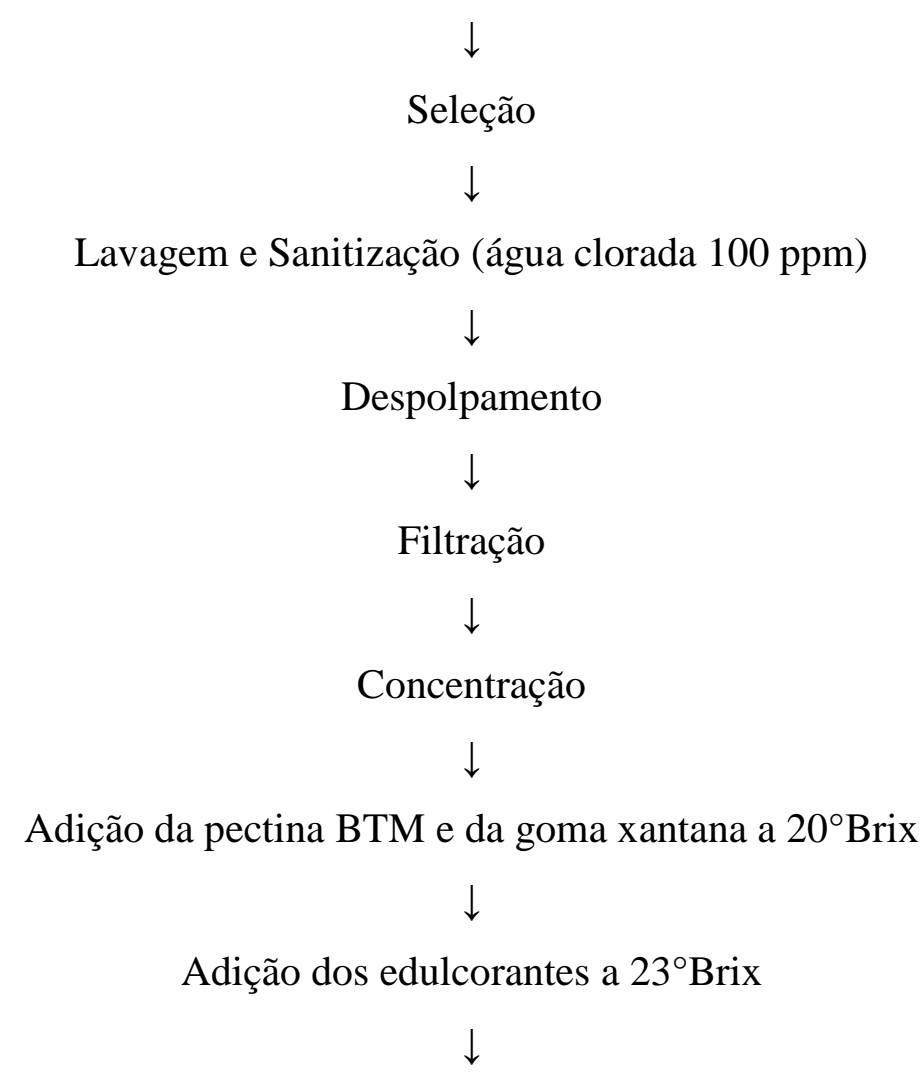

Adição do fosfato tricálcico, ácido cítrico e do sorbato de potássio a $25^{\circ} \mathrm{Brix}$

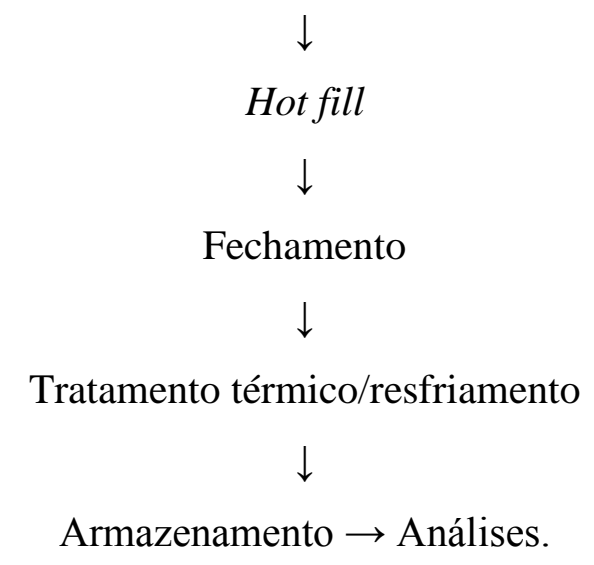

Depois do despolpamento o suco e a polpa foram filtrados utilizando uma tela até obter a separação do suco da parte fibrosa.

O processo de concentração foi realizado em recipiente inox a pressão atmosférica com aquecimento direto. $\mathrm{O}$ suco filtrado (com $11,5^{\circ}$ Brix) foi submetido à cocção até atingir $20^{\circ}$ Brix e, em seguida adicionou-se a pectina BTM previamente hidratada com água a $70^{\circ} \mathrm{C}$. Para essa hidratação utilizou para cada grama de pectina 10 partes de água destilada. Ao adicionar a pectina hidratada o teor de sólidos solúveis reduziu, sendo necessário aquecimento até atingir os $20^{\circ}$ Brix para então adicionar a goma xantana. 
A goma xantana, também, passou por um processo de hidratação com água a temperatura ambiente sendo que para cada g de goma xantana eram utilizadas 67 partes de água destilada.

Ao alcançar $23^{\circ}$ Brix foram adicionados os edulcorantes acessulfame de potássio e sucralose, de acordo com cada formulação, ambos dissolvidos em água. Com o teor de sólidos solúveis de $25^{\circ}$ Brix foram adicionados os demais ingredientes (o fosfato tricálcico, o ácido cítrico e o conservante sorbato de potássio, dissolvidos em água) sendo, em seguida, interrompido o aquecimento. A formulação diet foi submetida a aquecimento de aproximadamente $1 \mathrm{~h}$ e 20 minutos.

Figura 2 - Fluxograma do processamento da geleia de seriguela convencional.

$$
\text { Seriguela in natura } \rightarrow \text { Recepção }
$$

$\downarrow$

Seleção

$\downarrow$

Lavagem e Sanitização (água clorada 100ppm por 15 minutos)

$\downarrow$

Despolpamento $\rightarrow$ Bagaço

Filtração

$\downarrow$

Aquecimento do suco filtrado até a temperatura de $65-70^{\circ} \mathrm{C}$

Adição da pectina ATM e da sacarose

$\downarrow$

Concentração até o teor de sólidos solúveis de $70^{\circ}$ Brix

Adição do ácido cítrico

Hot fill (Enchimento a quente)

$\downarrow$

Fechamento $\rightarrow$ Inversão das embalagens

$\downarrow$

Tratamento térmico/Resfriamento

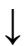

Armazenamento a temperatura ambiente $\rightarrow$ Análises 
Após o processamento, a geléia foi envasada a quente (hot fill) em embalagens de vidro, previamente esterilizadas a $100^{\circ} \mathrm{C} / 15 \mathrm{~min}$ com capacidade para $250 \mathrm{~g}$, fechadas com tampa de metal e invertidas para esterilização da tampa por 5 minutos. Em seguida, foi feito o tratamento térmico do produto em água aquecida a $100^{\circ} \mathrm{C}$ por 10 minutos e posteriormente o resfriamento.

A descrição das etapas de recepção até a etapa de filtração é similar à descrita para a geleia diet. $\mathrm{O}$ suco filtrado foi submetido a aquecimento até atingir a temperatura de $65-70^{\circ} \mathrm{C}$ quando então, adicionou-se a pectina ATM (a forma de diluição é semelhante a da pectina BTM usada para a geleia diet) e a sacarose (a relação da sacarose utilizada foi 1 parte de suco para 1 parte de sacarose). A concentração prosseguiu até atingir o teor de sólidos solúveis de $70^{\circ}$ Brix, quando então adicionou-se o ácido cítrico dissolvido em água. Após o processamento, a geleia foi envasada a quente (hot fill) em embalagens de vidro, previamente esterilizadas a $100^{\circ} \mathrm{C} / 15 \mathrm{~min}$ com capacidade para $250 \mathrm{~g}$, fechadas com tampa de metal e invertidas para esterilização da tampa por 5 minutos. Em seguida, foi feito o tratamento térmico do produto em água aquecida a $100^{\circ} \mathrm{C}$ por 10 minutos e posteriormente o resfriamento.

\section{Avaliação físico - química}

As características físico químicas determinadas nas geleias foram o $\mathrm{pH}$, a acidez titulável e o teor de sólidos solúveis. $\mathrm{O}$ pH foi determinado em pHmetro (Digimed DM 20), a acidez titulável por volumetria potenciométrica segundo IAL (2005) e teor de sólidos solúveis ( ${ }^{\circ}$ Brix) em refratômetro (Quimis modelo 109B, $\mathrm{n}^{\mathrm{o}}$ de série: 101131). Os açúcares totais foram analisados por Dubois (1956) utilizando-se espectrofotômetro (Biospectro) no comprimento de onda de $490 \mathrm{~nm}$.

\section{Avaliação sensorial}

O teste de aceitação foi usado para avaliar as formulações de geleia quanto a aceitação global e aos atributos cor, sabor característico, doçura, acidez e consistência do gel utilizando escala hedônica estruturada de nove pontos variando de 1 - desgostei extremamente a 9 - gostei extremamente. O pré-requisito para participar da análise era que os possíveis julgadores consumissem regularmente geleias e produtos dietéticos.

As análises foram realizadas no laboratório de Análise Sensorial da Universidade Estadual de Feira de Santana - BA. O painel consistia de 50 julgadores não treinados pertencentes à comunidade local e universitária, na faixa de 18 a 50 anos de ambos os sexos.

\section{Avaliação de cor}

A cor foi determinada em colorímetro da marca Colorquest Hunterlab (U.S. Company), sistema CIE L*a*b*,com leitura direta dos valores $\mathrm{L}^{*}$ (luminosidade) variando de 0 (preto) a 100 
(branco); $\mathrm{a}^{*}$, do verde (-) ao vermelho (+); $\mathrm{b}^{*}$, do azul (-) ao amarelo (+), com iluminante D65 e ângulo de $10^{\circ}$.

\section{Resultados e Discussão}

Avaliação físico química do suco de seriguela

Os resultados das análises físico químicas do suco de seriguela usado para o processamento das geleias encontram-se na Tabela 1 .

Tabela 1 - Determinações físico químicas do suco de seriguela.

\begin{tabular}{cc}
\hline Determinações & Resultados \\
\hline Sólidos solúveis totais $\left({ }^{\circ}\right.$ Brix $)$ & 16,8 \\
Ph & 3,1 \\
Acidez $(\%$ ácido cítrico) & 0,5 \\
\hline
\end{tabular}

A polpa da seriguela foi obtida no estádio de maturação ótimo da fruta, correspondendo a frutos com uma forte coloração alaranjada. O suco, obtido através de filtração da polpa, apresentou como características sensoriais e físico-químicas: cor amarela intensa a alaranjada, típica dos carotenóides da fruta, aroma típico e forte, pH igual a 3,1, uma concentração de sólidos solúveis de 16,8 ${ }^{\circ}$ Brix e acidez de 0,5. Esses valores foram próximos aos encontrados por Lima (2009).

As características apontam a seriguela como um fruto de interesse para a indústria de alimentos por apresentar teores de sólidos, $\mathrm{pH}$ e acidez em quantidades relevantes para diversos produtos.

\section{Avaliação físico química das geleias}

Os resultados das análises físico químicas das geleias de seriguela diet e convencional encontram-se na Tabela 2.

Tabela 2 - Determinações físico químicas das geleias de seriguela diet (formulações 1 a 5) e convencional.

\begin{tabular}{cccccc}
\hline Formulações & $\mathbf{p H}$ & Brix & Acidez (\% de ácido cítrico) & Açúcares totais * & $\begin{array}{c}\text { Valor calórico } \\
\text { (Kcal/100g) }\end{array}$ \\
\hline 1 & $3,1^{\mathrm{b}}$ & $24,4^{\mathrm{c}}$ & $1,0^{\mathrm{c}}$ & $26,0^{\mathrm{c}}$ & 104,0 \\
2 & $3,2^{\mathrm{b}}$ & $31,7^{\mathrm{b}}$ & $1,2^{\mathrm{a}}$ & $22,0^{\mathrm{d}}$ & 88,0 \\
3 & $3,1^{\mathrm{b}}$ & $32,4^{\mathrm{b}}$ & $1,2^{\mathrm{ab}}$ & $28,0^{\mathrm{b}}$ & 112,0 \\
4 & $3,2^{\mathrm{b}}$ & $26,3^{\mathrm{c}}$ & $1,1^{\mathrm{b}}$ & $22,0^{\mathrm{d}}$ & 88,0 \\
5 & $3,2^{\mathrm{b}}$ & $25,4^{\mathrm{c}}$ & $0,9^{\mathrm{d}}$ & $18,0^{\mathrm{e}}$ & 72,0 \\
Convencional & $2,9^{\mathrm{a}}$ & $66,0^{\mathrm{a}}$ & $0,5^{\mathrm{e}}$ & $52,2^{\mathrm{a}}$ & 208,8 \\
\hline
\end{tabular}

Letras diferentes na mesma coluna evidenciam diferenças significativas pelo teste de Tukey $(p<0,05)$.

*Obs. O percentual dos açúcares totais nas formulações dietéticas (de 1 a 5) é com relação a frutose, já da formulação convencional é com relação a sacarose.

As formulações dietéticas não diferiram significativamente entre si em relação ao $\mathrm{pH}$, que apresentou um valor médio de 3,2. Esse valor é bem próximo ao encontrado por Lamante et al. 
(2005) para geleia de maracujá diet. A pectina BTM é capaz de formar gel em uma ampla faixa de pH, com ou sem adição de açúcar na presença de pequenas quantidades de cálcio (CARDOSO et al. 2003; FU e RAO, 2001; VENTURA, 2004). Segundo Seravalli e Ribeiro (2004) a pectina BTM é menos sensível ao $\mathrm{pH}$ que a ATM, podendo formar géis na faixa de 2,5 a 6,5. Diante disso, o pH encontrado no estudo está dentro da faixa de formação do gel e também da faixa considerada livre de deterioração por bactérias produtoras de toxinas.

Os valores de acidez das formulações dietéticas variaram de 0,9\% a 1,2\% (em ácido cítrico). Essas variações podem ser atribuídas às diferenças de acidez das frutas utilizadas. Estes valores se enquadram na faixa de acidez para diferentes geleias de fruta sendo similares aos encontrados por Nachtigall et al. (2004) em geleias light de amora preta, menores que os encontrados por Barcia et al. (2010) em geleias de jambolão light e maiores que os obtidos por Zambiazi et al. (2006) em geleias de morango light .

Em relação ao teor de sólidos solúveis, a variação nas formulações dietéticas foi de $24,4^{\circ}$ Brix a $32,4^{\circ}$ Brix. Jesus e Mamede (2013) encontraram valores de $25^{\circ}$ Brix a $28^{\circ}$ Brix para geleia de caju de reduzido valor calórico e Nachtigall et al. (2004) encontraram um valor médio de $35^{\circ}$ Brix em geleias light de amora preta. Segundo Campos e Candido (1994), a concentração de sólidos solúveis indicada para geleias dietéticas é de $25^{\circ}$ Brix, uma vez que não tem adição de açúcares e a concentração é alcançada somente com a retirada da água, sem o suporte do açúcar para elevar o teor de sólidos. A geleia convencional apresentou valor de sólidos solúveis significativamente superior $\left(66^{\circ}\right.$ Brix) ao das demais geleias dietéticas devido à maior concentração de açúcares presentes na formulação da geleia convencional.

A concentração de açúcares totais nas formulações dietéticas (\% em frutose) variou de $18 \%$ a $28 \%$. Esses açúcares são os naturalmente presentes na fruta, e que permaneceram no produto final após o processamento, não tendo sido feita nenhuma adição desse ingrediente. Jesus e Mamede (2013) encontraram valores de açúcares totais na faixa de 13 a 19,27 para geleia de caju de reduzido valor calórico.

De acordo com a Portaria n ${ }^{\text {2 } 29, ~ d e ~} 13$ de janeiro de 1998 (BRASIL, 1998), um produto que não tenha adição de açúcares, mas contenha os açúcares naturais dos ingredientes, entrará na categoria de alimentos para dietas de ingestão controlada de açúcares, e essa alegação precisa vir no rótulo. Nesse caso, a legislação também permite a utilização do termo diet na rotulagem do produto.

Os valores calóricos das geleias foram determinados de acordo com a RDC 360 de 23 de dezembro de 2003 (BRASIL, 2003). Para esse cálculo não foi levado em consideração os teores de proteínas e lipídios das geléias uma vez que as geleias não são as principais fontes desses nutrientes. O valor calórico das 5 formulações das geleias de seriguela diet variaram entre 72,0 e 112,0 $\mathrm{Kcal} / 100 \mathrm{~g}$ e o da formulação convencional com adição de açúcar foi de 208,8 Kcal/100g. Isso 
mostra que todas as formulações sem adição de açúcar apresentaram redução calórica superior a $25 \%$ em relação a geleia convencional atendendo ao percentual mínimo de redução estipulado pela legislação (Portaria nº 27, de 13 de janeiro de 1998) para o produto ser considerado light.

\section{Avaliação sensorial}

Os resultados do teste de aceitação sensorial da geleia de seriguela diet encontram-se na tabela 3.

Tabela 3 - Resultados do teste de aceitação sensorial da geleia de seriguela diet.

\begin{tabular}{ccccccc}
\hline Formulações & $\begin{array}{c}\text { Aceitação } \\
\text { global }\end{array}$ & Cor & $\begin{array}{c}\text { Sabor } \\
\text { Característico }\end{array}$ & Doçura & Acidez & Consistência do gel \\
\hline 1 & $5,8^{\mathrm{ab}}$ & $6,7^{\mathrm{a}}$ & $5,7^{\mathrm{ab}}$ & $5,4^{\mathrm{b}}$ & $5,8^{\mathrm{a}}$ & $6,3^{\mathrm{a}}$ \\
2 & $5,7^{\mathrm{ab}}$ & $6,1^{\mathrm{ab}}$ & $5,5^{\mathrm{b}}$ & $5,8^{\mathrm{ab}}$ & $5,7^{\mathrm{a}}$ & $5,6^{\mathrm{b}}$ \\
3 & $5,5^{\mathrm{b}}$ & $6,5^{\mathrm{a}}$ & $5,6^{\mathrm{b}}$ & $5,8^{\mathrm{ab}}$ & $5,8^{\mathrm{a}}$ & $5,2^{\mathrm{b}}$ \\
4 & $6,3^{\mathrm{a}}$ & $5,5^{\mathrm{b}}$ & $6,3^{\mathrm{a}}$ & $6,3^{\mathrm{a}}$ & $6,1^{\mathrm{a}}$ & $6,7^{\mathrm{a}}$ \\
5 & $6,1^{\mathrm{ab}}$ & $6,4^{\mathrm{a}}$ & $5,9^{\mathrm{ab}}$ & $5,9^{\mathrm{ab}}$ & $5,9^{\mathrm{a}}$ & $6,4^{\mathrm{a}}$ \\
\hline
\end{tabular}

Letras diferentes na mesma coluna evidenciam diferenças significativas pelo teste de Tukey $(\mathrm{p}<0,05)$.

As notas atribuídas para a aceitação global corresponderam a gostei ligeiramente na escala hedônica estruturada. Dentre as 5 formulações estudadas a que obteve maior nota foi a formulação 4 que apresentou em sua formulação a combinação dos edulcorantes sucralose e acessulfame de potássio. Com relação a doçura essa foi também a formulação mais aceita pelos provadores. Os diversos tipos de edulcorantes apresentam características diferentes, que podem beneficiar um produto quando combinados. Segundo Campos e Candido (1994) a combinação de dois ou mais edulcorantes podem eliminar algumas limitações presentes ao serem utilizados isoladamente. Ao combinar edulcorantes obtêm níveis mais elevados de doçura (sinergismo) aperfeiçoando o gosto doce, mascarando sabores residuais, produzindo perfil de doçura o mais próximo possível ao da sacarose. Almeida et al (2009) ao estudarem a aceitabilidade sensorial de goiabadas desenvolvidas com diferentes edulcorantes verificaram que as goiabadas elaboradas com as combinações de sucralose e acessulfame de potássio tiveram uma melhor aceitação pelos consumidores comprovando os resultados obtidos no presente estudo.

A variação do atributo cor está relacionada, possivelmente, a caramelização parcial dos açúcares presentes na matéria prima e maior degradação de pigmentos uma vez que as geleias dietéticas, por não terem adição de açúcar, requerem um tempo mais prolongado para se alcançar o teor de sólidos solúveis. Vendramel et al. (1997) enfatizaram que o uso da pectina BTM, agente 
gelificante das geleias com reduzido valor calórico, ocasiona também alteração na coloração dos produtos.

Mesmo com diferença significativa na acidez titulável, os resultados da sensorial mostraram que os julgadores não perceberam essa diferença nas cinco formulações estudadas. Isso mostra que a proporção dos edulcorantes nas formulações foi eficiente para mascarar o sabor ácido.

As geleias com reduzido valor calórico foram sensorialmente classificadas como “consistentes", portanto, apresentaram consistência adequada ao tipo de produto. Nachtigall e Zambiazi (2006) ao estudarem as características sensoriais de geleia de hibisco com reduzido valor calórico e Barcia et al. (2010) ao estudarem as características sensoriais de geleia de jambolão com reduzido valor calórico encontraram valores próximos aos obtidos nesse estudo para o parâmetro consistência do gel.

\section{Avaliação de cor}

A Tabela 4 mostra os valores médios das determinações instrumentais de cor das formulações de geleia de seriguela diet.

Tabela 4 - Valores médios das determinações instrumentais de cor das formulações de geleia de seriguela diet.

\begin{tabular}{cccc}
\hline Formulações & Parâmetro L & Parâmetro a & Parâmetro b \\
\hline 1 & $50,4^{\mathrm{a}}$ & $11,7^{\mathrm{bc}}$ & $43,2^{\mathrm{b}}$ \\
2 & $50,1^{\mathrm{a}}$ & $12,4^{\mathrm{b}}$ & $43,7^{\mathrm{b}}$ \\
3 & $48,6^{\mathrm{b}}$ & $11,4^{\mathrm{c}}$ & $43,7^{\mathrm{b}}$ \\
4 & $44,0^{\mathrm{c}}$ & $13,3^{\mathrm{a}}$ & $39,6^{\mathrm{c}}$ \\
5 & $48,2^{\mathrm{b}}$ & $12,3^{\mathrm{b}}$ & $40,5^{\mathrm{c}}$ \\
\hline
\end{tabular}

Letras diferentes na mesma coluna evidenciam diferenças significativas pelo teste de Tukey $(\mathrm{p}<0,05)$.

A cor é o primeiro contato que se tem com os alimentos, a qual se associa aos tratamentos tecnológicos aplicados e aos processos que os mesmos podem sofrer, além de nos permitir avaliar em conjunto com outras análises a qualidade destes alimentos (PERÉZ - ALVAREZ et al. 1999). É utilizada como parâmetro para a seleção de muitos produtos e relaciona-se com a percepção da aparência pelo consumidor.

Segundo Prati et al. (2005), na determinação objetiva da cor dos produtos o valor L expressa a luminosidade ou claridade da amostra e pode variar de 0 a 100. Assim sendo, quanto mais próximo ou mais distante de 100, mais escura ou mais clara será a amostra. Por sua vez, valores positivos de $\mathrm{a}^{*}$ mais elevados indicam tendência a coloração vermelha e os negativos de coloração verde, enquanto que os valores positivos de $b^{*}$ expressam maior intensidade de amarelo e os negativos maior intensidade de azul. 
Os valores de $\mathrm{L}^{*}$, obtidos nesse estudo, indicaram a predominância de baixa luminosidade, com valores entre 44,0 e 50,4. Analisando-se as coordenadas $\mathrm{a}^{*}$ e b*, observa-se que os valores de $a^{*}$, estão entre 11,4 e 13,3 e b* entre 39,6 e 43,7. A característica visual das formulações com esses valores apresentou cor amarronzada provavelmente pela formação dos pigmentos em maior intensidade resultantes do processamento.

Jesus e Mamede (2013) ao estudarem geleia de caju de reduzido valor calórico encontraram valores de luminosidade $\left(30,40\right.$ e 40,87) e valores da coordenada $b^{*}(28,07$ e 33,58$)$ menores aos encontrados nesse estudo. Já os valores da coordenada a*, encontrada por esses autores, estão entre 12,28 e 15,30. Salgado et al (2009) ao analisar geleias funcionais sem adição de açúcar a base de cajá e acerola encontraram para a coordenada a* valores entre 7,1 a 17,28; para a coordenada b* entre 30,29 a 44,16 e para L* entre 45,53 a 51,1. Essas variações são provavelmente atribuídas ás condições de processamento para formação do gel.

A cor das geleias expressa pelos parâmetros estudados de colorimetria, indica o índice de transformação natural dos alimentos frescos, assim como, as mudanças ocorridas no processo industrial. As geleias dietéticas, por não terem adição de açúcar, requerem um maior tempo de cozimento até se alcançar o teor de sólidos solúveis desejados. O aquecimento prolongado apresenta efeitos negativos como: escurecimento não enzimático, devido a reação de Maillard, caramelização e destruição de pigmentos. Esses efeitos geram alterações na cor final do produto.

\title{
4. Conclusão
}

De acordo com os dados físico-químicos e sensoriais das geleias de seriguela diet pode-se concluir que as geléias diet apresentam uma boa opção para o aproveitamento da seriguela sendo uma alternativa de fornecimento de produtos de baixa caloria. As geléias diet apresentaram boa aceitação pelo consumidor, sendo que a melhor opção foram as formulações que apresentaram a combinação dos dois edulcorantes, podendo ser uma opção para indivíduos que precisam adotar uma dieta utilizando alimentos para fins especiais.

\begin{abstract}
Currently have seen a great demand for sugar-free foods. This trend has encouraged the use of fruits as ingredients in many products such as jam, allowing the production of low-calorie products. Hog plum (Spondias purpurea L.) is a tropical fruit commonly produced in the Brazilian Northeast, and use it in jam production can ensure the consumption of fruit during the year and reduce production losses, because it is naturally perishable fruit. Thus, the aim of this work was the development and characterization of hog plum jam prepared without added sugar, and use of sucralose and acesulfame potassium, subjecting it to physico chemical, sensory and color analysis. The jam presented physical-chemical characteristics similar to the others presented in the literature. Sensory analysis revealed that the best formulation had the combination of the two
\end{abstract}


sweeteners. With respect to colorimetric analysis, jam showed brownish probably by the formation of pigments in higher intensity of the processing. The results found in this study are of great interest for agribusiness, as it opens a new possibility of harnessing hog plum with an alternative supply of a low calorie product.

Key-words: hog plum; jam; low calorie; sweeteners.

\section{Referências}

ALMEIDA, L. E.; RAMOS, A. M.; BINOTI, M. L.; CHAUCA, M. C.; STRINGHETA, P. C. Análise de perfil de textura e aceitabilidade sensorial de goiabadas desenvolvidas com diferentes edulcorantes. Revista Ceres, v.56, p. 697704, 2009.

BAKER, R. A.; BERRY, N.; HUI, Y. H.; BARRETT, D.M. Fruit Preserves and Jams. In: BARRETT, D.M.; SOMOGYI, L.; RAMASWAMY, H. Processing Fruits. Flórida: CRC Press, Boca Raton, 2005. p. 113-125.

BARCIA, M. T.; MEDINA, A. L.; ZAMBIAZI, R. C. Características físico-químicas e sensoriais de geléias de Jambolão. Boletim do Centro de Pesquisa e Processamento de Alimentos (Ceppa), v. 28, n. 01, p. 25-36, 2010.

BINNS, N. M. Sucralose - all sweetness and light. British Nutrition Foundation. Nutrition Bulletin, v. 28, p. 53-58, 2003. http://dx.doi.org/10.1046/j.1467-3010.2003.00307.x

BRASIL. Ministério da Saúde. Agência Nacional de Vigilância Sanitária. Portaria n³18, de 24 de novembro de 1995. Aprova o uso de Sucralose com a função de edulcorante em alimentos e bebidas dietéticas. Diário Oficial da União, Poder Executivo, Brasília, 28 nov. 1995.

BRASIL. Ministério da Saúde. Agência Nacional de Vigilância Sanitária. Portaria no 29 de 13 de janeiro de 1998. Regulamento Técnico referente a Alimentos para Fins Especiais. Diário Oficial da União, Poder Executivo, Brasília, 30 mar. 1998.

BRASIL. Ministério da Saúde. Agência Nacional de Vigilância Sanitária. Portaria no 27 de 13 de janeiro de 1998. Regulamento Técnico referente à Informação Nutricional Complementar. Diário Oficial da União, Poder Executivo, Brasília, 13 jan. 1998.

BRASIL. Ministério da Saúde. Agência Nacional de Vigilância Sanitária. Resolução da Diretoria Colegiada, RDC no 360, 23 de dezembro de 2003. Regulamento Técnico sobre Rotulagem Nutricional de Alimentos Embalados, tornando obrigatória a rotulagem nutricional. Diário Oficial da União, Poder Executivo, Brasília, 26 dez. 2003.

BRASIL. Ministério da Saúde. Agência Nacional de Vigilância Sanitária. Resolução da Diretoria Colegiada, RDC nº 18, 24 de março de 2008. Regulamento Técnico que autoriza o uso de aditivos edulcorantes em alimentos, com seus limites respectivos limites máximos. Diário Oficial da União, Poder Executivo, Brasília, 25 mar. 2008.

CAMPOS, A. M.; CANDIDO, L. M. B. Comportamento de géis de pectinas amidadas em presença de diferentes adoçantes e teores variados de cálcio. Boletim do Centro de Pesquisa e Processamento de Alimentos (Ceppa), v.12, n.01, p.39-54, 1994.

CARDOSO, S., COIMBRA, M., LOPES DA S. Temperature dependence of the formation and melting of pectin $-\mathrm{Ca}^{2+}$ networks: A rheological study. Food Hydrocollloids, v. 17, p. 801-807, 2003. http://dx.doi.org/10.1016/S0268005X(03)00101-2

DUBOIS, M.; GILlES, K. A.; HAMILTON, J. K.; REBERS, P. A.; SMITH, F. Colorimetric method for determination of sugar and related substances. Analytical Chemistry, v. 28, p.350-356, 1956. http://dx.doi.org/10.1021/ac60111a017

EMBRAFARMA.

Acessulfame

Potássio,

<http://www.embrafarma.com.br/produtos/AcessulfamePotassio.pdf>. Acesso em out. 2010.

disponível em:

FU, J. T.; RAO, M. A. Rheology and structure development during gelation of low methoxyl pectin gels: the effect of sucrose. Food Hydrocolloids, v.15, p. 93-100, 2001. http://dx.doi.org/10.1016/S0268-005X(00)00056-4 
GRANADA, G. G.; ZAMBIAZI, R. C.; MENDONÇA, C. R. B.; SILVA, E. Caracterização física, química, microbiológica e sensorial de geléias light de abacaxi. Ciência e Tecnologia de Alimentos, v. 25, p. 629-635, 2005. http://dx.doi.org/10.1590/S0101-20612005000400002

HOLM, K., WENDIM, K., HERMANSSON, A. M. Sweetness and texture perception in mixed pectin gels with $30 \%$ sugar and a designed rheology. Food Science and Technology, v. 42, p.788-795, 2009.

INSTITUTO ADOLFO LUTZ. Métodos físico químicos para análise de alimentos. Brasília: Editora MS, 2005.

JESUS, M. A. C. L. de; MAMEDE, M. E. de O. Adding value to cashew pseudo fruit: physicalchemical, textural and sensory characteristics of low calorie cashew apple jam. Wudpecker Journal of Food Technology, v. 01, p. 022-033, 2013.

LAMANTE, A. C. B.; DADA, M. A.; FURQUIM, M.; GRAVENA, C.; BELLARDE, F. B.; LUCIA, F.D. Obtenção de geleia “diet” elaborada com suco de maracujá. Revista Uniara, n.16, p.189-197, 2005.

LEON, J.; SHAW, P. E. Spondias: the red mombin and releated fruits. In: NAGY, S.; SHAW, P.E.; WARDOWSKI, W.F. Fruits of tropical and subtropical origin, composition, properties and uses., Flórida: Lake Alfred, 1990. p. $116-126$.

LIMA, I. da C. G. S. Seriguela (Spondias purpurea L.): propriedades físico-químicas e desenvolvimento de geléia de doce de corte e aceitabilidade desses produtos. Seropédica, 2009. 87 f. Dissertação (Mestrado em Ciência e Tecnologia de Alimentos) - Instituto de Tecnologia - Universidade Federal Rural do Rio de Janeiro.

LOFGREN, C; HERMANSSON, A. M. Synergistic rheological behaviour of mixed HM/LM pectin gels. Food Hydrocolloids, v. 21, p. 480-486, 2007. http://dx.doi.org/10.1016/j.foodhyd.2006.07.005

MARTINS, V. B. Perfil Sensorial de Suco Tropical de Cupuaçu (Theobroma grandiflorum Schum) com valor calórico reduzido. Campinas, 2008. 142 f. Tese (Doutorado em Alimentos e Nutrição) - Faculdade de Engenharia de Alimentos - Universidade Estadual de Campinas.

MENDONÇA, C. R. B.; ZAMBIAZI, R. C.; GULARTE, M. A.; GRANADA, G. G. Características sensoriais de compotas de pêssego light elaboradas com sucralose e acessulfame K. Ciência e Tecnologia de Alimentos, v. 25, p. 401-407, 2005. http://dx.doi.org/10.1590/S0101-20612005000300002

NACHTIGALL, A. M.; ZAMBIAZI, R. C.; CARVALHO, D. S. de. Geléia light de hibisco: características físicas e químicas. Alimentos e Nutrição, v.15, n.02, p.155-161, 2004.

NACHTIGALL, A. M.; ZAMBIAZI, R. C. Geléias de hibisco com reduzido valor calórico: características sensoriais. Boletim do Centro de Pesquisa e Processamento de Alimentos (Ceppa) v. 24, n.01, p. 47-58, 2006.

PÉREZ - ALVAREZ, J. A.et al. El color de los alimentos. Technology Food. Esperanza, n.08, p. 32 - 43 , 1999.

PRATI, P.; MORETTI, R. H.; CARDELLO, H. M. A. M. Elaboração de bebida composta por mistura de garapa parcialmente clarificada-estabilizada e suco de frutas ácidas. Revista Ciência e Tecnologia de Alimentos, v. 25, n. 01, p.147-152, 2005. http://dx.doi.org/10.1590/S0101-20612005000100024

SALGADO, P. de L. Produção de geleias funcionais sem adição de açúcar a base de cajá e acerola. XX CONGRESSO BRASILEIRO DE ECONOMIA DOMÉSTICA, VIII ENCONTRO LATINO-AMERICANO DE ECONOMIA DOMÉSTICA e I ENCONTRO INTERCONTINENTAL DE ECONOMIA DOMÉSTICA, 2009, Fortaleza CE, disponível em <http//:http://www.xxcbed.ufc.br/arqs/gt6/gt6_64.pdf.> Acesso em out. 2011.

SANDROU, D. K.; ARVANITOYANNIS, I. S. Low fat calorie foods: current state and perspectives. Food Science, v. 40, n.05, p. 427-447, 2000 .

SERAVALli, E. A. G.; RIBEIRO, E. P. Química de Alimentos. São Paulo: Edgard Blucher Ltda, 2004.

VENDRAMEL, S. M. R.; CÂNDIDO, L. M. B.; CAMPOS, A. M. Avaliação reológica e sensorial de geléias com baixo teor de sólidos solúveis com diferentes hidrocolóides obtidas a partir de formulações em pó. Boletim do Centro de Pesquisa e Processamento de Alimentos (Ceppa) v. 15, n.01, p.37-56,1997. 
VENTURA, F. C. Desenvolvimento de doce de fruta em massa funcional de valor calórico reduzido, pela combinação de goiaba vermelha e yacon desidratados osmoticamente e acerola. Campinas, $2004.194 \mathrm{f}$. Dissertação (Mestrado em Tecnologia de Alimentos) - Faculdade de Engenharia de Alimentos - Universidade Estadual de Campinas.

ZAMBIAZI, R. C., CHIM, J. F., BRUSCATTO, M. Avaliação das características e estabilidade de geléias light de morango. Alimentos e Nutrição, v.17, p.165-170, 2006.

WIET, S. G.; BEYTS, P. K. Sensory characteristics of sucralose and other high intensity sweetners. Journal of Food Science, v. 57, p. 1014-1019, 1992. http://dx.doi.org/10.1111/j.1365-2621.1992.tb14345.X

WOLFHARD, R.; LIPINSKI, G. W. R. The new intense sweetener acesulfame K. Food chemistry, v. 16, p. 259-69, 1985. http://dx.doi.org/10.1016/0308-8146(85)90120-7

Submetido em 18 dez. 2013, Aceito para publicação em 23 jun. 2014, Publicado em 28 dez. 2014.. 